\title{
Study of Morphological and Germination Parameters of Legume Crops Vigna Mungo L. Treated with Cement Dust
}

\author{
Rajasubramanian Devarajan ${ }^{1}$, Narendra $\mathrm{K}^{2}$, Navya Krishna Ram ${ }^{3}$ and Krishna Ram Hanumappa ${ }^{3 *}$
}

\begin{abstract}
Field experiment was conducted with blackgram var. Vamban 3. By different levels $\left(5,10,15\right.$ and $20 \mathrm{~g} \mathrm{~m}^{-2}$ day $\left.^{-1}\right)$ of the cement dust to investigate the effect of foliar application on plant growth. The morphological growth parameters (shoot length, root length, number of root nodules, total leaf area, fresh weight, and dry weight) of blackgram were recorded periodically. The yield parameters (number of pods, number seeds per pod, dry weight of pod, 100 seed weight and final yield) were recorded at the time of harvest. Both parameters were found to be decreased with the increasing levels of the applied cement dust.
\end{abstract}

Key Word: Vigna mungo L, Morphology, Root nodules, Cement dust Pollution.

\section{INTRODUCTION}

Air pollution has become a major threat to the survival of plants in the industrial areas. Air pollutants, emitted from various industries in particularly, cause damage of plant leaves, impairs plant growth, and limit productivity according to the sensitiveness of the plants to pollutants (Ulrich, 1984). Thus, pollution stress can alter plant growth and quality and the effects are often extensive (Sagar et al., 1982). Rapid urbanization and industrialization in recent years has escalated the demand for cement not only in India but worldwide. The accompanying growth of cement industries in India has consequently magnified the pollution problem. Cement industries are regarded to be highly-pollution prone, especially with regard to particulate emission. They also play a vital role in the imbalance of the environment and produces air pollution hazard.

Cement industries pollute the environment in the form of dust in the surrounding areas and their products escape during factory processing (Uma et al., 1994; Ayanbamiji and Ogundipe, 2010). Cement dusts can be emitted at every stage of the manufacturing process of the cement: extraction of the raw material, crushing, production, packaging and loading of finished cement (Bankole, 2003). Solid particles released from cement factory can have negative effects on air quality. The particles can enter into soil as dry, humid or occult deposits and can undermine its physico-chemical properties. Cement dust spread along a large area through wind, rain, etc., and are accumulated in and on plants, animals, and soil and it shows negative effects (Ayvaz, 1992). Accumulation of particulates on leaves may cause foliar injury, reduction in yield, changes in the rate of photosynthesis, transpiration, uptake and accumulation of minerals and energy in plants. In addition, it caused various diseases in humans beings such as asthma, chronic bronchisis, tuberculosis, head ache and lung cancer in human beings. The objective of this study, therefore, was to investigate the effect of cement dust application on the growth characters of Vigna mungo L.

\section{MATERIALS AND METHODS}

Seed material:The seeds of blackgram (Vigna mungo L. Hepper var. Vamban 3) were procured from National Pulse Research Station, Regional Research Station of Tamil Nadu Agricultural University located at Vamban, Pudukkottai district, Tamil Nadu, India. The healthy seeds were chosen and used for both laboratory and field experiments.

\section{Germination studies}

The healthy seeds of blackgram var. Vamban 3 were surface sterilized with 0.2 per cent of $\mathrm{HgCl}_{2}$ for two minutes and thoroughly washed with tap water. Fifteen seeds were equispacially arranged in plastic cups $(3 \mathrm{~cm}$ in height $12 \mathrm{~cm}$ width) with various amount $(5,10,15$ 20,25 and $30 \mathrm{~g}$ ) of cement dust each mixed with $200 \mathrm{~g}$ soil (Raajasubramanian et al., 2011a\&b). The control set was maintained without cement dust. Uniform irrigation was done by tap water. Three replicates were maintained for each treatment including the control. The germination percentage, seedling length, seedling fresh weight and dry weight were measured on the 7 th day after old seedling. The values of vigour index and tolerance index were also calculated (Plate-I).

Germination percentage: Germination refers to the initial appearance of radicle by visual observation. The number of seeds germinated in each treatment was counted on each and every day upto 7 th day after

\footnotetext{
${ }^{1}$ Department of Botany, AnnamalaiUniversity, AnnamalaiNagar,

Chidambaram, Tamilnaidu, India ${ }^{1}$

${ }^{2-}$ Department of Biology, MES College of arts Commerce and Science, Karnataka, India

${ }^{3-}$ DOS in Zoology, University of Mysore, Mysore, Karnataka, India

*Corresponding author email:krishnaram.mys@gmail.com.

Received April 19, 2018, Accepted August 16, 2018
} 
sowing. Germination percentage was calculated by using the following formula:

Germination percentage $=\frac{\text { Total number of seeds germinated }}{\text { Total } \text { number of seeds sown }} \times 100$

Seedling length ( $\mathbf{C m} /$ seedling): Fifteen seedlings were randomly selected on 7 th day from each treatment to record the seedling length. The length, of the blackgram var. Vamban 3 seedlings was measured by using a centimeter scale and the values were recorded.

Fresh weight and dry weight (g/seedling): Fifteen seedlings were measured and their fresh weight was taken by using an electrical single pan balance. They were dried in a hot air oven at $80^{\circ} \mathrm{C}$ for $24 \mathrm{hrs}$ and their dry weights were recorded with an electrical single pan balance and they were expressed in grms/seedling.

Vigour index: Vigour index of the seedlings was calculated by using the formula proposed by AbdulBaki and Anderson (1973), as follows:

Vigour index $=$ Germination percentage $\times$ seedling length .

Tolerance index: Tolerance index of the seedlings were calculated by using the formula proposed by Turner and Marshal (1972) as follows:

Tolerance index $=\frac{\text { Mean length of longest root in the treatment }}{\text { Mean length of longest root in the control }}$

\section{Field preparation:}

The field was thoroughly ploughed three times before seed sowing. The entire field was irrigated with bore well water for two days before sowing. Blackgram seeds were sown with a spacing of $20 \times 20 \mathrm{~cm}$. Field management were employed under usual agronomical practices.

Cement dust treatment: Different amounts (5, 10, 15, and $20 \mathrm{~g} \mathrm{~m}-2$ day-1) of cement dust were applied daily on the aerial parts of the experimental crops. The crops grown without cement dust were treated as the control.

Plant samples were collected randomly at various stages $(15,30,45$ and $60 \mathrm{DAS})$ of its growth and used for recording morphometrical observations like: shoot length, root length, number of root nodule, total leaf area, fresh weight, dry weight, and yield of crop plants. Five plants were selected from each treatment including control for recording various morphological parameters.

Shoot length and root length: Five plant samples were collected at 15, 30, 45 and 60 DAS to record the shoot length and root length by using $\mathrm{cm}$ scale.

Number of root Nodule: Five plants from each plot with intact roots were removed with the help of digging fork. The root with root nodules were carefully separated from the soil and thoroughly washed with tap water to remove the soil. Pink coloured nodules were counted as effective nodules and the number of nodules were recorded.

Total leaf area: The total leaf area was calculated by measuring the length and width of the leaf as described by Yoshida et al. (1972), as follows:

Leaf area $\left(\mathrm{cm}^{2}\right)=\mathrm{K} \times$ length $\times$ breadth

Where

$\mathrm{K}=$ Kemp's constant (for dicot leaves 0.66)

Fresh weight and Dry weight: The plant samples taken for morphometric studies were used for the determination of fresh weight and dry weight of plant material. They were dried in a hot air oven at $80^{\circ} \mathrm{C}$ for $24 \mathrm{hrs}$ and their dry weight was measured by using an electrical single pan balance.

\section{Yield Parameters}

Number of pods per plant: Five plants were selected at random in each plot and the number of pods per plant was recorded.

Number of seeds per pod: The seeds were removed from the pod and the total number of seeds was counted and expressed in number of seeds per pod.

Dry weight of pods per plant: The pods were separated from the plant and their dry weights were measured by using an electrical single pan balance and it was expressed in $\mathrm{g} /$ plant.

Hundred Seed weight: 100 mature seeds were collected from test crop and their dry weights were recorded by using an electrical single pan balance.

Seed yield: The yield of black gram was collected from which experimental plot and expressed in kilogram per hectare.

\section{RERSULTS}

\section{Germination studies}

The effect of cement dust on germination studies of blackgram are presented in Figs 1 and 2 (Plate-I). The highest germination percentage (100), seedling length (19.36 cm/seedling), fresh weight $(0.986 \mathrm{~g} /$ seedling), dry weight (0.349 g/seedling), vigour index (1836.0) were observed in the control plants. The lowest germination percentage (21) was recorded in $30 \mathrm{~g}$ cement dust treatment mixed with $200 \mathrm{~g}$ of soil.

The lowest seedling length $(9.31 \mathrm{~cm} / \mathrm{seedling})$, fresh weight $(0.364 \mathrm{~g} /$ seedling $), \quad$ dry weight $(0.135$ $\mathrm{g} /$ seedling), vigour index (600.4) and tolerance index (0.59) were observed in $25 \mathrm{~g}$ cement dust treatment mixed with $200 \mathrm{~g}$ soil. Germination of seeds was noticed in $30 \mathrm{~g}$ of cement dust mixed with $200 \mathrm{~g}$ of soil and there is lowest number of seedling growth was observed 
in this concentration, when compared to other treatments.

\section{Field experiment}

Shoot length: The effect of cement dust on shoot length of blackgram at various stages of growth is presented in Fig 3. The highest shoot length $(16.685,21.843,28.019$ and $34.802 \mathrm{~cm} /$ plant) was obtained at $15,30,45$ and 60 DAS of control plant. Similarly, the lowest shoot length (5.705, 9.113, 13.142 and $20.436 \mathrm{~cm} /$ plant) was recorded in the $20 \mathrm{~g} \mathrm{~m}^{-2}$ day $^{-1}$ of cement dusted plants at $15,30,45$ and 60 DAS respectively.

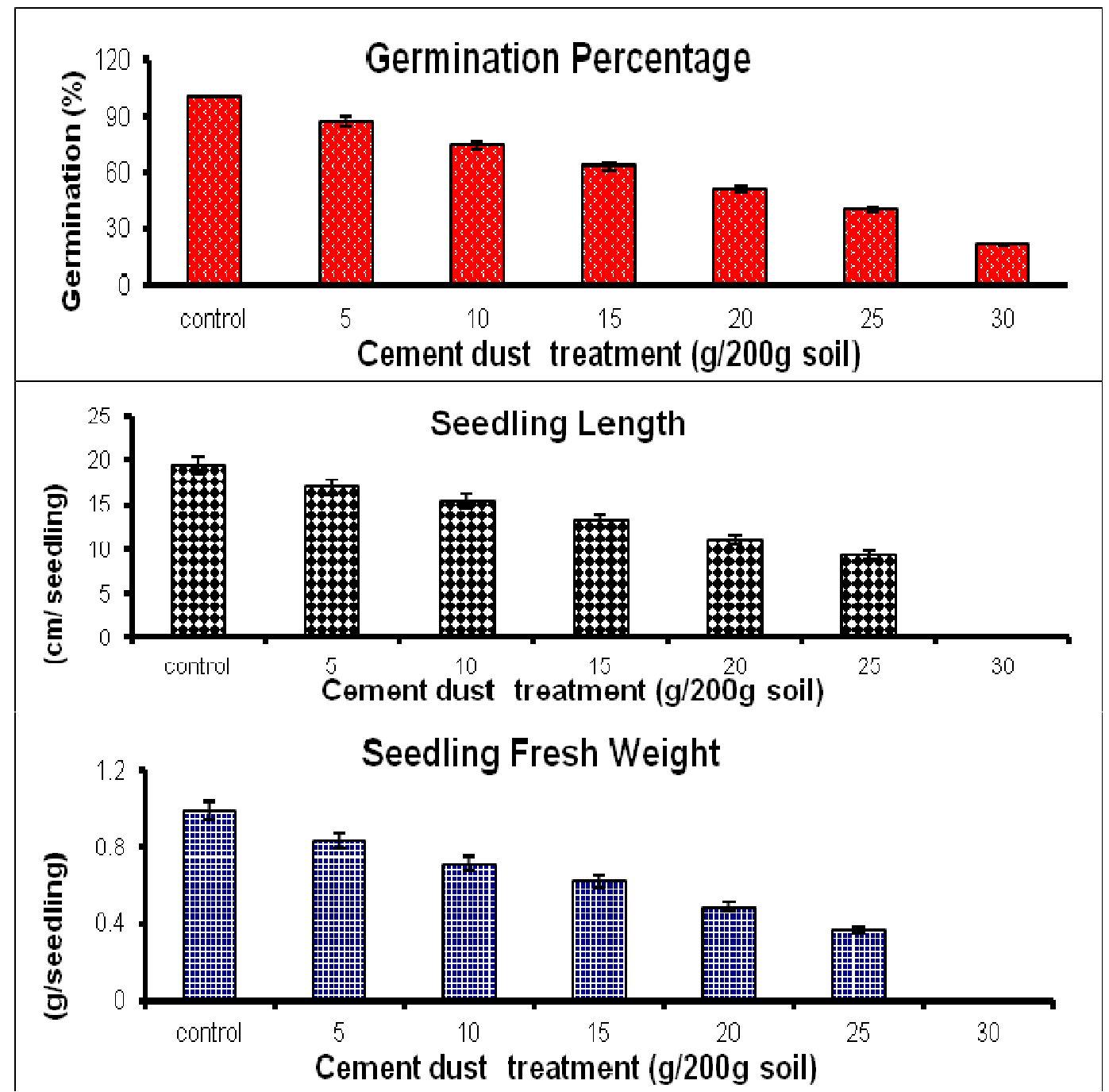

Fig. 1. Effect of cement dust on germination percentage $(\%)$, seedling length $(\mathrm{cm} / \mathrm{seedling})$ and fresh weight (g/seedlings) of blackgram seedlings 


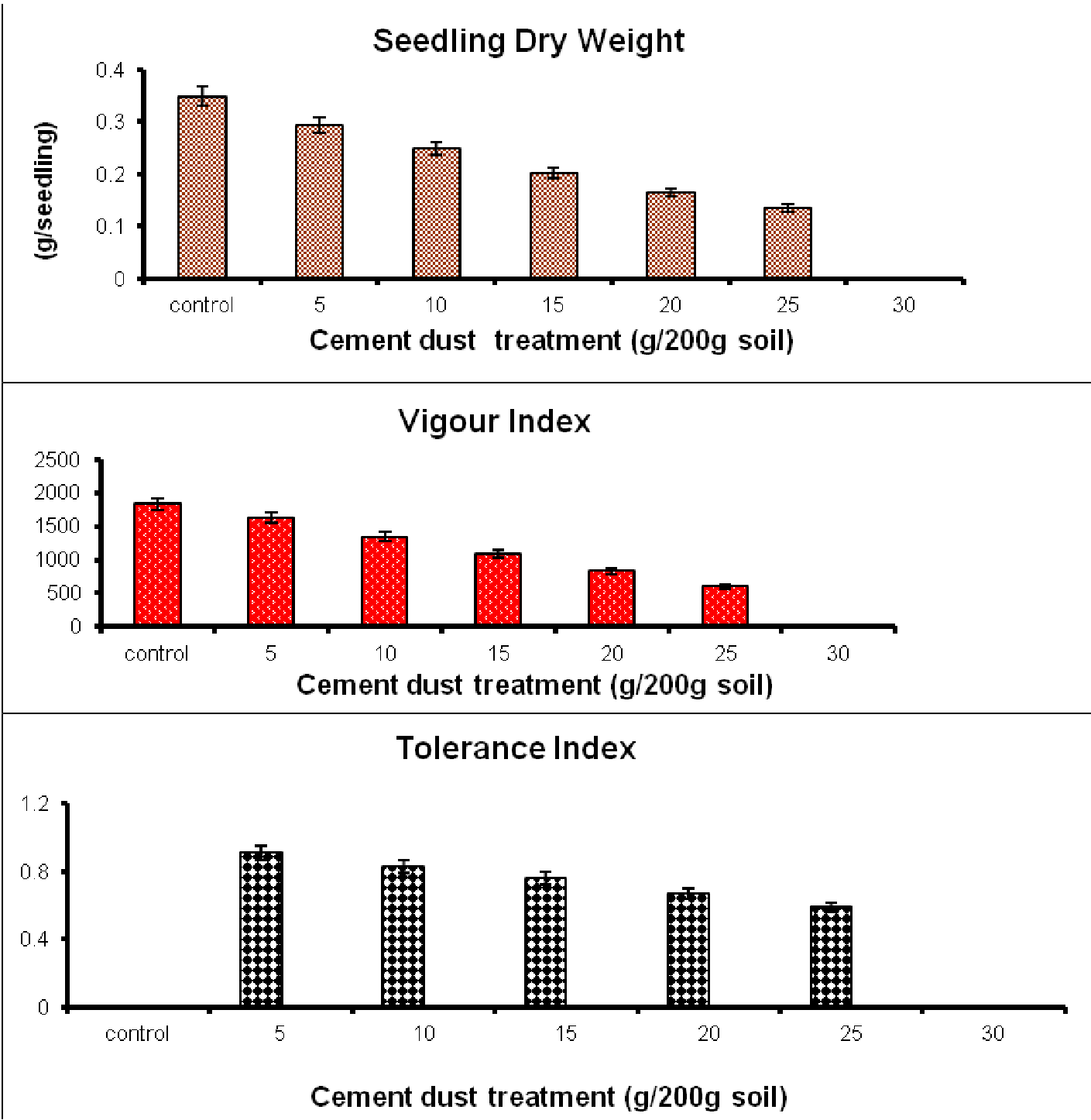

Fig. 2. Effect of cement dust on dry weight (g/seedling), vigour index and tolerance index of blackgram seedlings

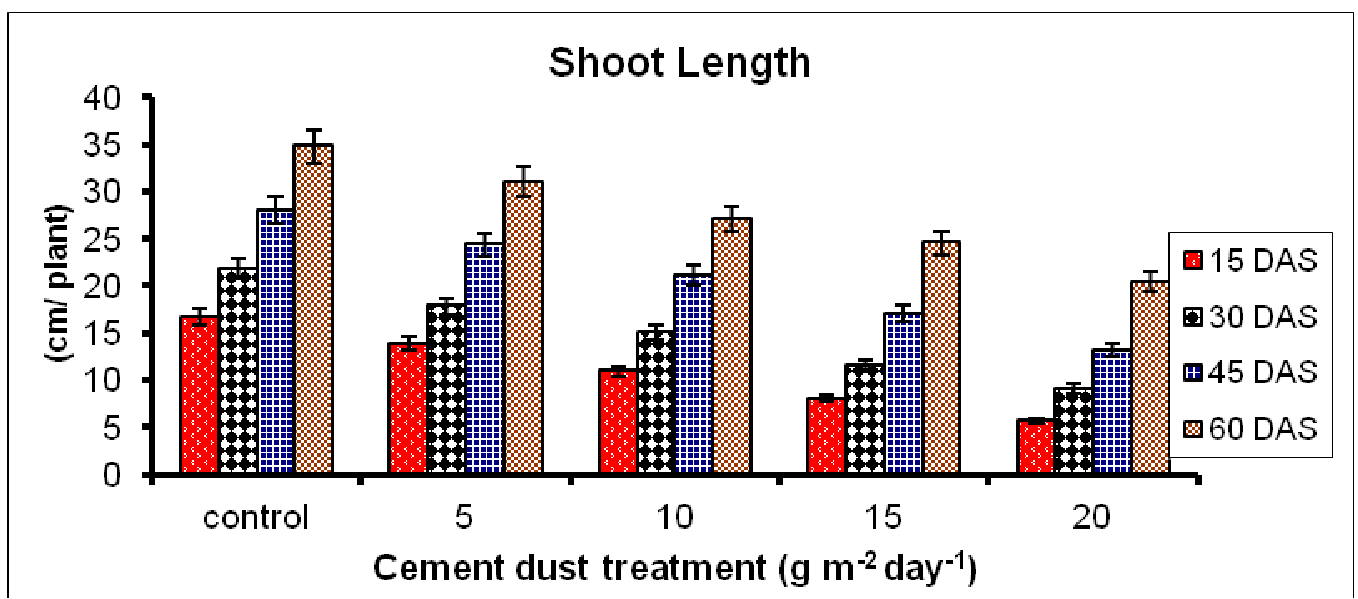

Fig. 3. Effect of cement dust on shoot length ( $\mathrm{cm} /$ plant) of blackgram at various stages of its growth 
Root length: The effect of various amount of cement dust on root length of blackgram at various stages of its growth was given in fig 4 . The highest root length (10.218, 13.803, 17.791 and $21.293 \mathrm{~cm} /$ plant) was observed in control plants at 15, 30, 45 and 60 DAS respectively. Similarly, the lowest root length (3.511, $4.762,8.134$ and $12.652 \mathrm{~cm} /$ plant) was observed in $20 \mathrm{~g}$ $\mathrm{m}^{-2}$ day $^{-1}$ cement dusted plants at $15,30,45$ and 60 DAS respectively.

Number of root nodules: The effect of cement dust on number of root nodule of blackgram was presented in Fig 5. The highest number of root nodules (29.22, $38.32,50.23$ and 45.23 nodule/plant) was observed at
$15,30,45$ and 60 DAS in control plants. Similarly, the lowest number of root nodules $(7.45,13.28,19.96$ and 16.28 nodule/plant) was recorded in the $20 \mathrm{~g} \mathrm{~m}^{-2}$ day $^{-1}$ of cement dusted plants at 15,30, 45 and 60 DAS respectively.

Total leaf area: The effect of cement dust on total leaf area of blackgram was presented in Fig 6. The highest total leaf area $(54.519,78.323,86.402$ and $71.01 \mathrm{~cm}^{2} /$ plant) was recorded in control plants. The lowest total leaf area $(19.859,29.985,58.785$ and $41.258 \mathrm{~cm}^{2} /$ plant) was observed in $20 \mathrm{~g} \mathrm{~m}^{-2}$ day $^{-1}$ of cement dusted plant at 15, 30, 45 and 60 DAS respectively.

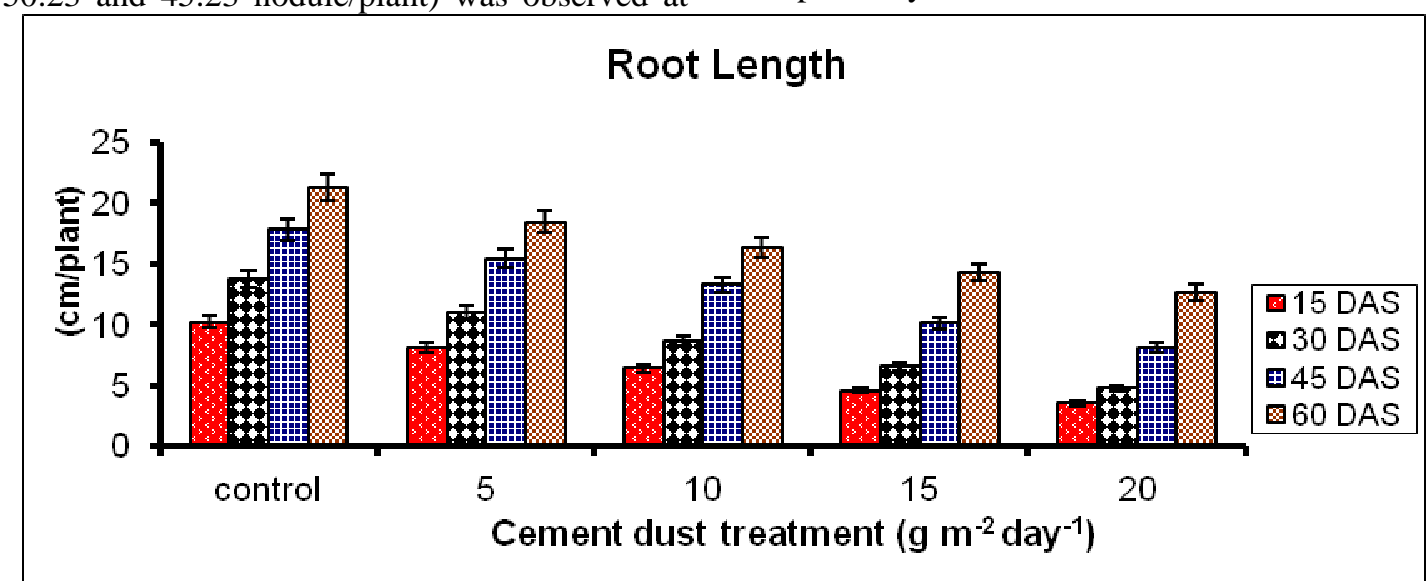

Fig. 4. Effect of cement dust on root length $(\mathrm{cm} /$ plant $)$ of blackgram at various stages of its growth

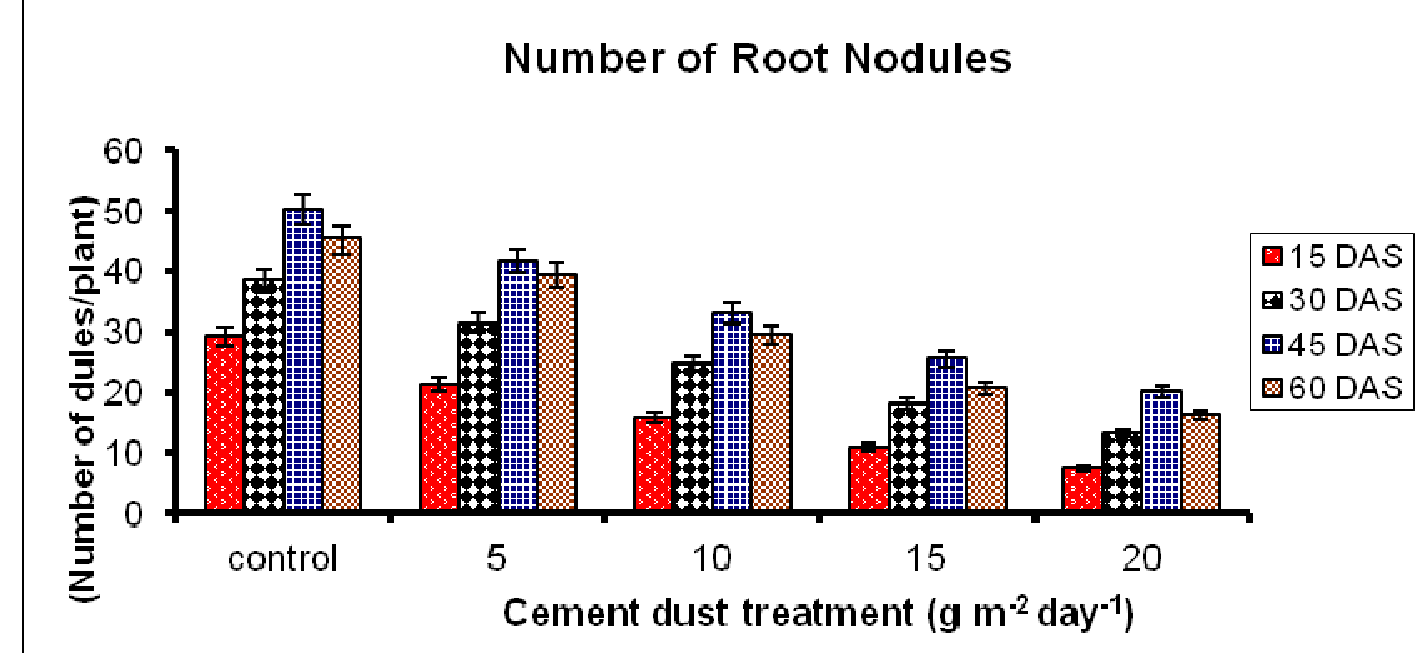

Fig.5. Effect of cement dust on number of root nodule (nodules/plant) of blackgram at various stages of its growth 


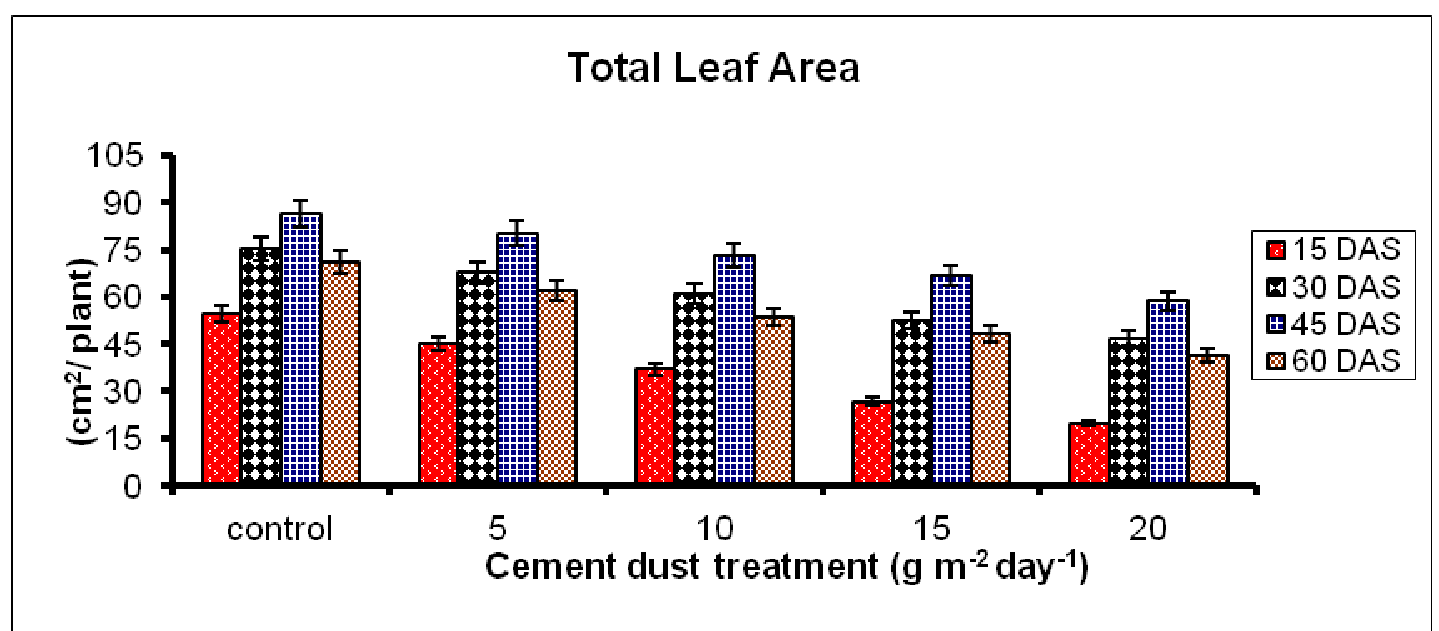

Fig. 6. Effect of cement dust on total leaf area $\left(\mathrm{cm}^{2} /\right.$ plant $)$ of blackgram at various stages of its growth

Fresh weight of shoot: The influence of cement dust on fresh weight of blackgram shoot was shown in the Fig 7. The highest fresh weight of shoot (21.951, $35.901,49.914$ and $71.241 \mathrm{~g} /$ plant) was observed in 15 , 30,45 and 60 DAS of control plants. The lowest fresh weight of shoot $(4.974,11.551,17.249$ and 37.174 $\mathrm{g} /$ plant) was observed in $20 \mathrm{~g} \mathrm{~m}-2$ day- 1 cement dusted plants at 15, 30, 45 and 60 DAS respectively.

Dry weight of shoot: The effect of cement dust on dry weight of blackgram shoot was recorded in Fig 8 . The highest dry weight of shoot $(6.773,11.519,14.663$ and $20.337 \mathrm{~g} /$ plant) was recorded in control plant at 15,30 ,
45 and 60 DAS respectively. The lowest dry weight of shoot (1.996, 3.564, 6.058 and 11.005 g/plant) was recorded at 15, 30, 45 and $60 \mathrm{DAS}$ in $20 \mathrm{~g} \mathrm{~m}^{-2}$ day $^{-1}$ cement dusted plants.

Fresh weight of root: The effect of cement dust on fresh weight of blackgram root was shown in Fig 9. The highest fresh weight of root $(5.997,9.978,13.817$ and $17.847 \mathrm{~g} /$ plant) was recorded in control plants. The lowest fresh weight of root $(1.605,3.089,6.101$ and $9.101 \mathrm{~g} /$ plant) was recorded in $20 \mathrm{~g} \mathrm{~m}^{-2}$ day $^{-1}$ cement dusted plants at 15, 30, 45 and 60 DAS respectively.

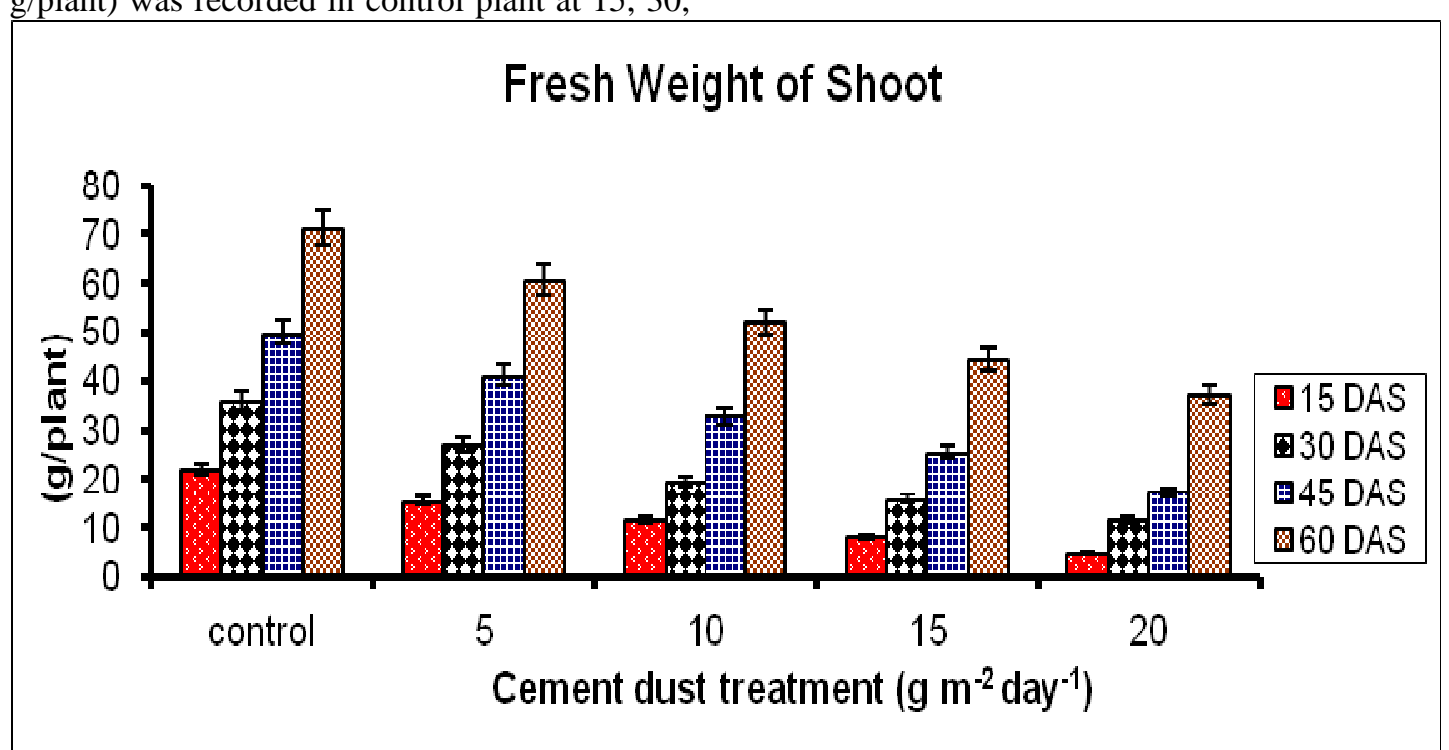

Fig.7. Effect of cement dust on fresh weight of shoot (g/plant) of blackgram at various stages of its growth 


\section{Dry Weight of Shoot}

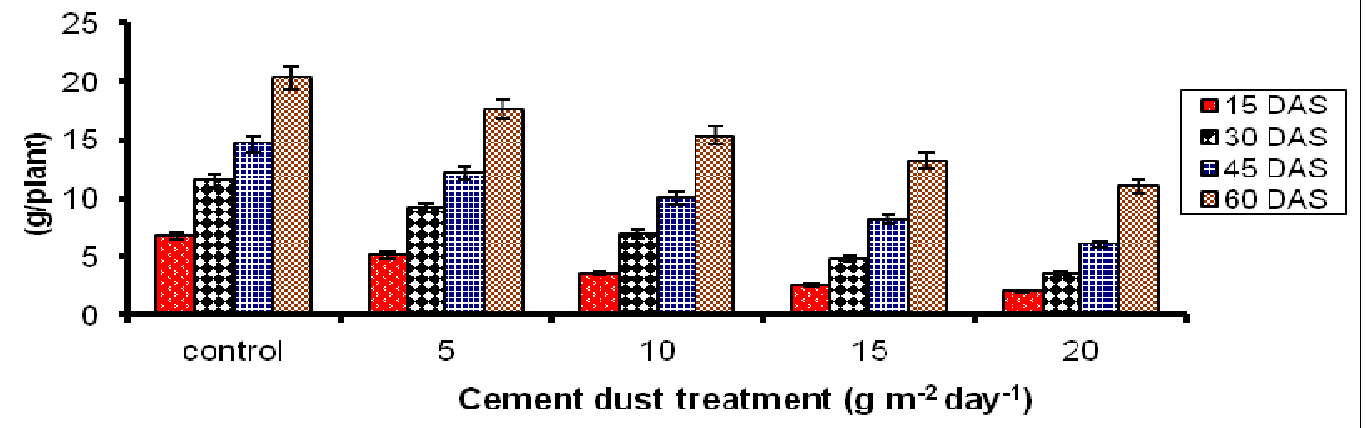

Fig. 8. Effect of cement dust on dry weight of shoot (g/plant) of blackgram at various stages of its growth

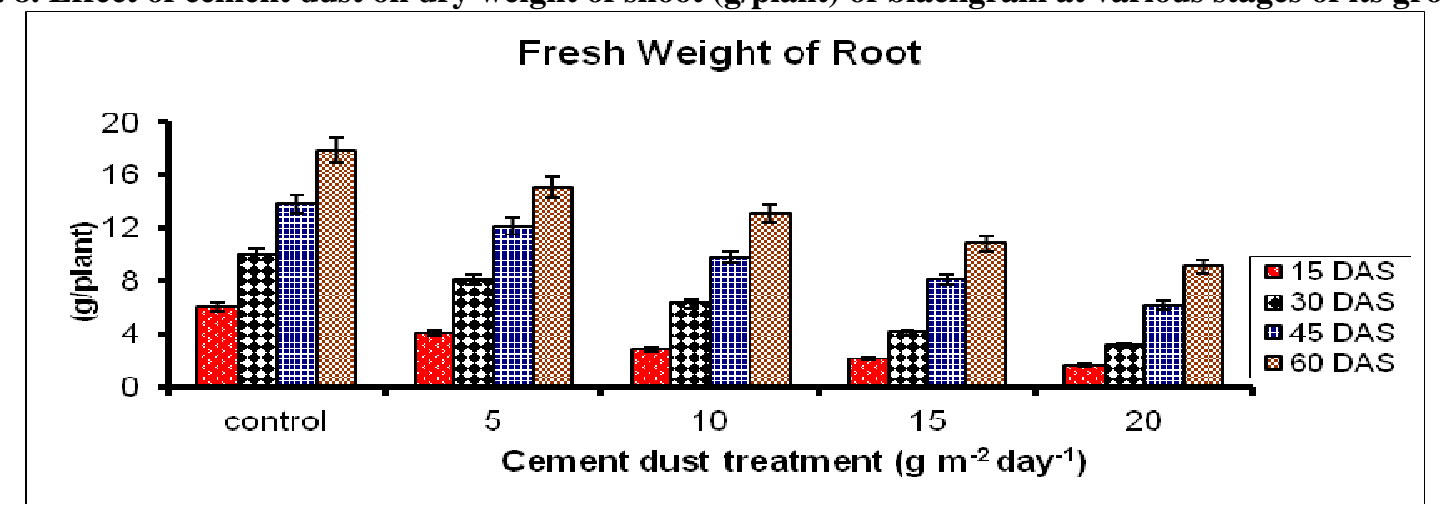

Fig.9. Effect of cement dust on fresh weight of root (g/plant) of blackgram at various stages of its growth

Dry weight of root: Influence of cement dust on dry weight of blackgram root was recorded in Fig 10. The highest dry weight of root $(1.491,2.849,3.909$ and 4.968 $\mathrm{g} /$ plant) occurs in 15, 30, 45 and 60 DAS of control plants respectively. The lowest dry weight of root $(0.404,0.956$, 1.402 and $1.984 \mathrm{~g} /$ plant) was recorded in $20 \mathrm{~g} \mathrm{~m}^{-2}$ day $^{-1}$ cement dusted plants at $15,30,45$ and 60 DAS respectively.

Yield Parameters:The effect of various amount of cement dust on yield parameters of blackgram was given in Figs from 11 to 15 . The highest number of pods (22.3/plant), number of seeds (10.5/pod), dry weight of pod $\left(0.985 \mathrm{~g}^{-1}\right.$ plant), 100 seed weight $(7.2 / \mathrm{g})$ and yield (655.2 $\mathrm{kg}^{-1}$ hectares) were recorded in control plants at the time of harvest. The lowest number of pods (10.9/plant), number of seeds (3.8/plant), dry weight of pod $(0.431 \mathrm{~g} / \mathrm{plant}), 100$ seed weight $(3.5 / \mathrm{g})$ and yield $(332.3$ $\mathrm{kg} /$ hectare) were recorded in $20 \mathrm{~g} \mathrm{~m}^{-2}$ day $^{-1}$ cement dusted plants at harvest stage

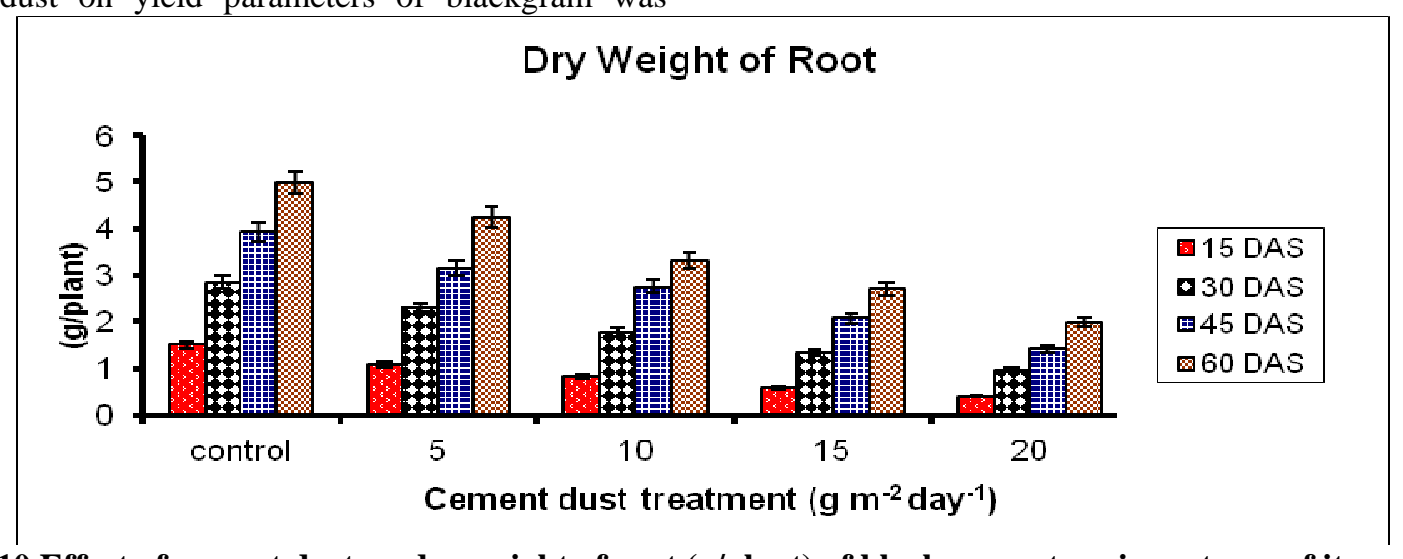

Fig. 10.Effect of cement dust on dry weight of root (g/plant) of blackgram at various stages of its growth 


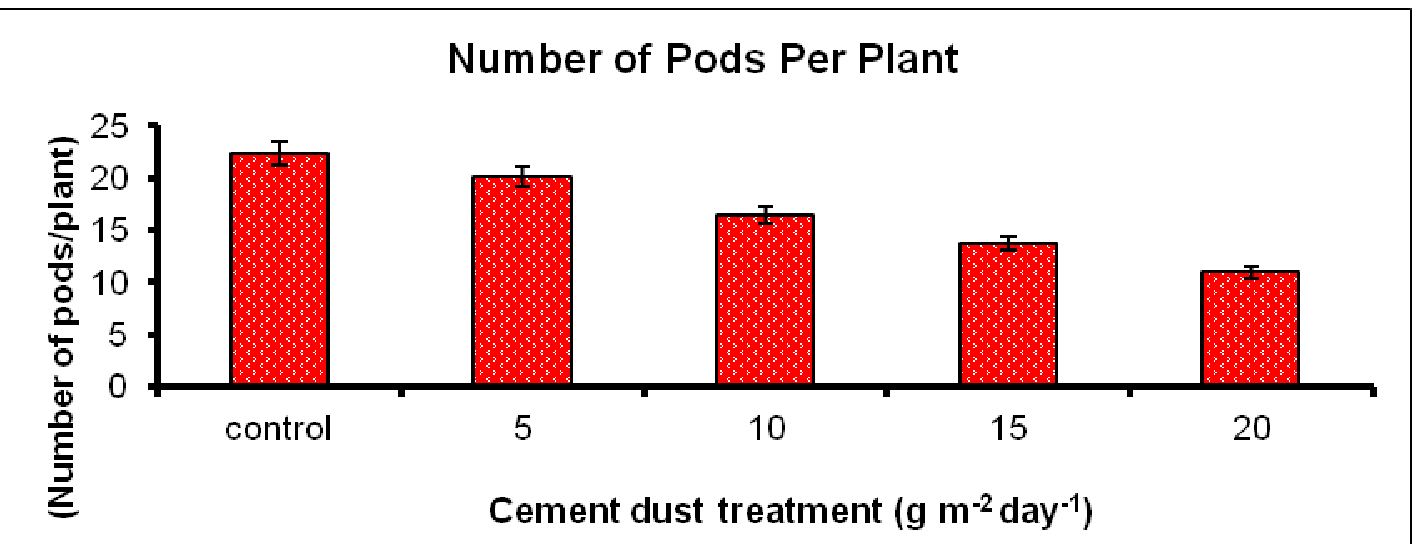

Fig. 11. Effect of cement dust on number of pods (pods/plant) of blackgram at yield stage

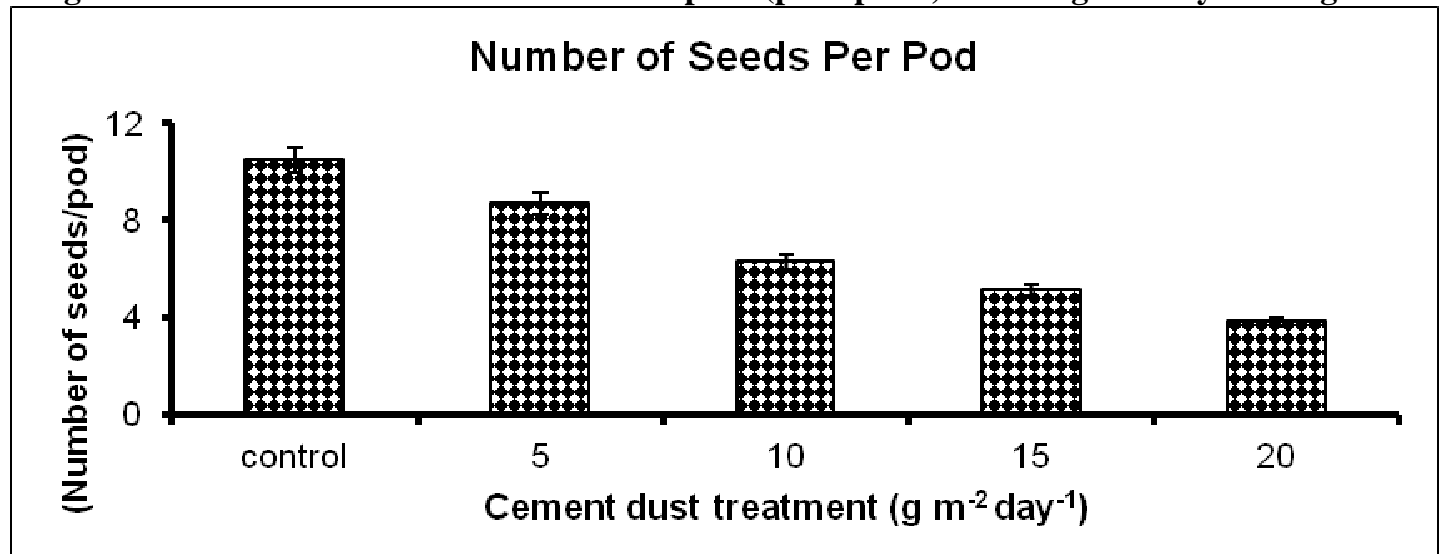

Fig. 12.Effect of cement dust on number of seeds per pod (seeds/pod) of blackgram at yield stage Dry Weight of Pod

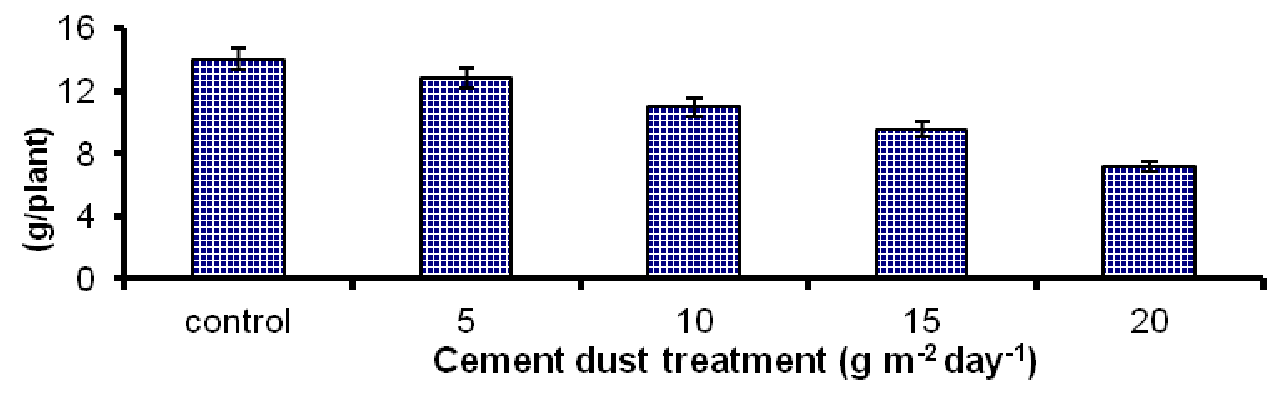

Fig.13. Effect of cement dust on dry weight of pod (g/plant) of blackgram at yield stage

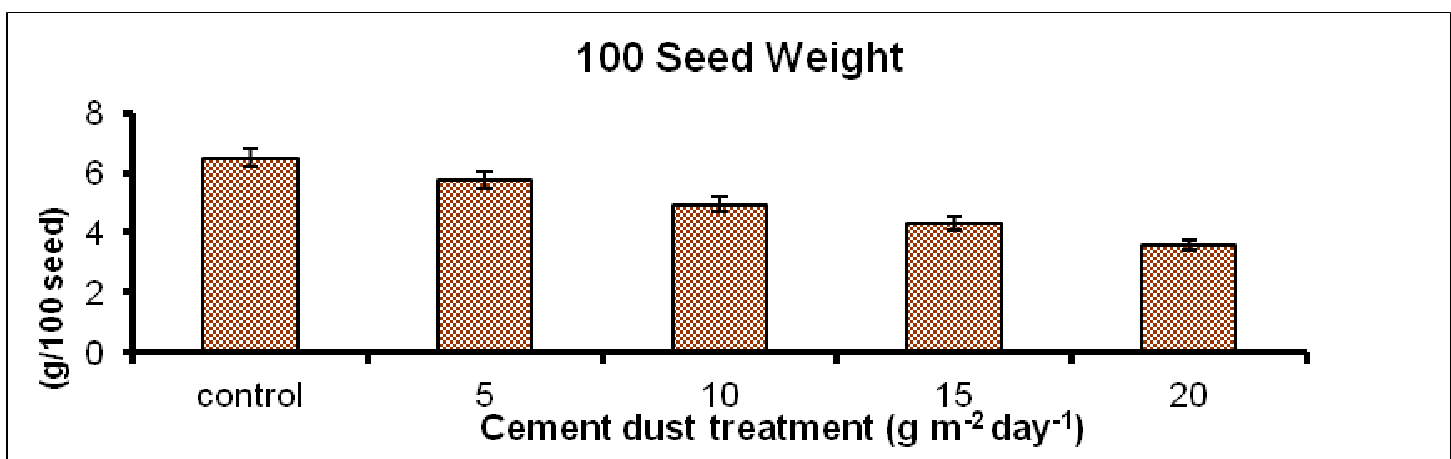

Fig. 14. Effect of cement dust on 100 seed weight (g/100 seed) of blackgram at yield stage 


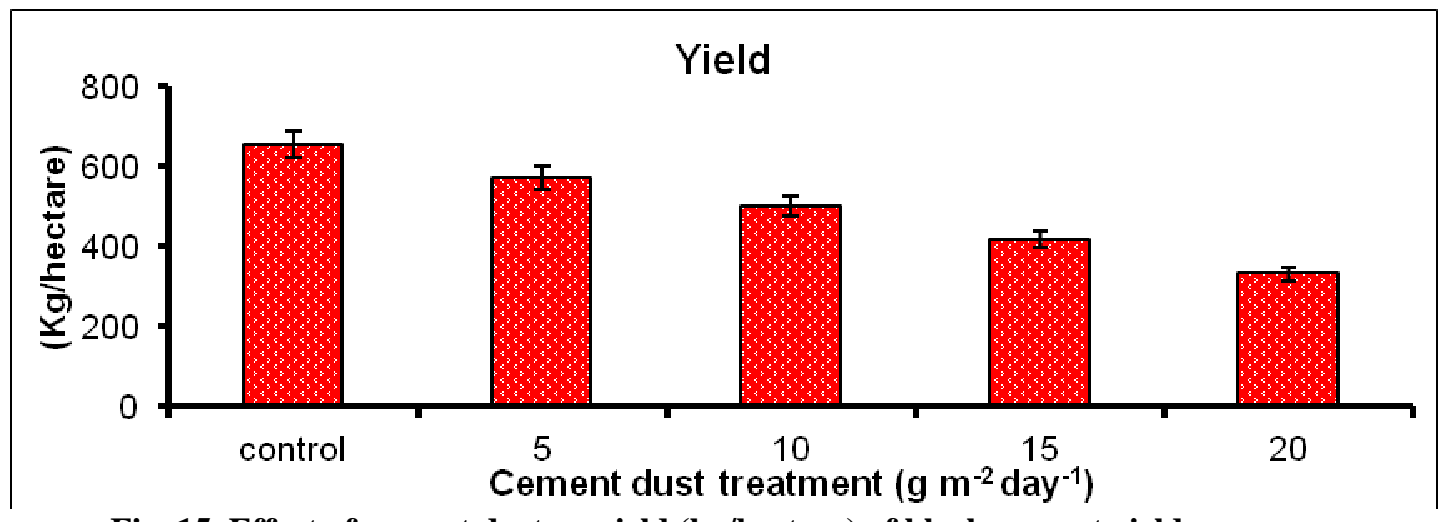

Fig. 15. Effect of cement dust on yield (kg/hectare) of blackgram at yield

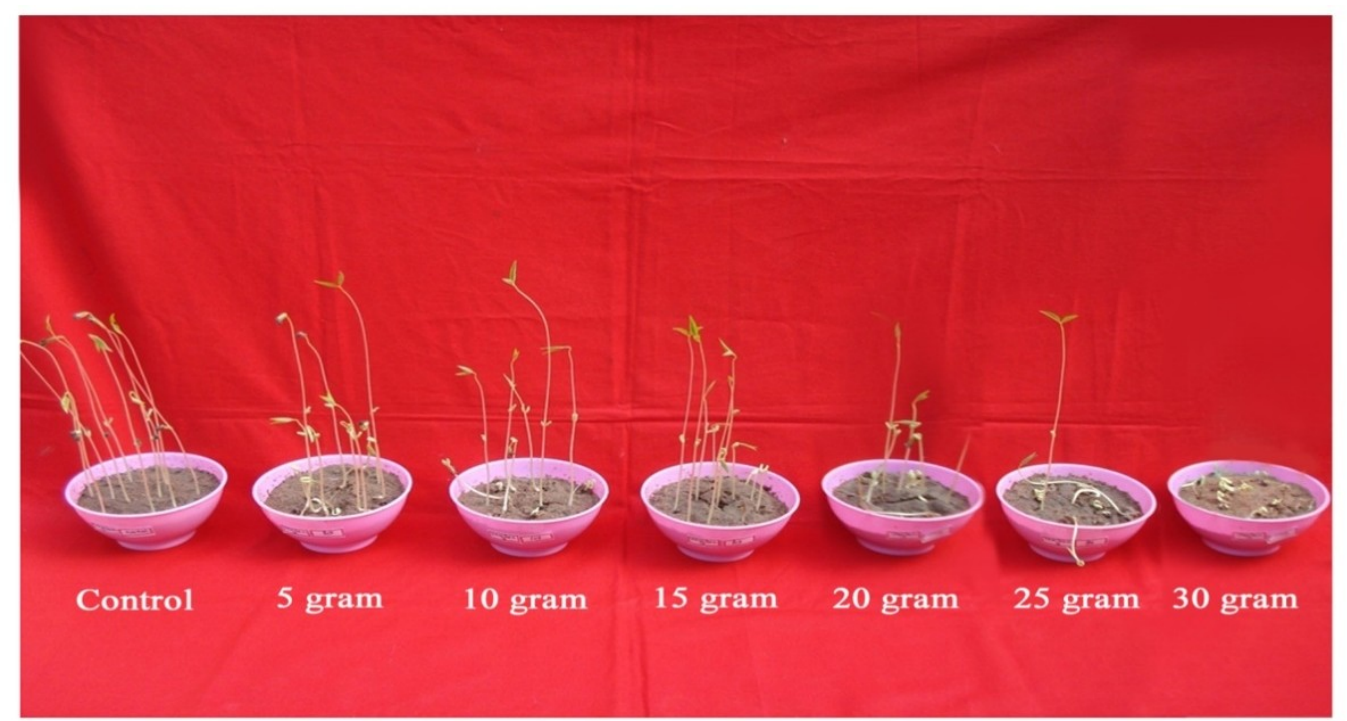

PLATE-I. Germination studies of Blackgram grown in soil mixed with various levels of cement dust

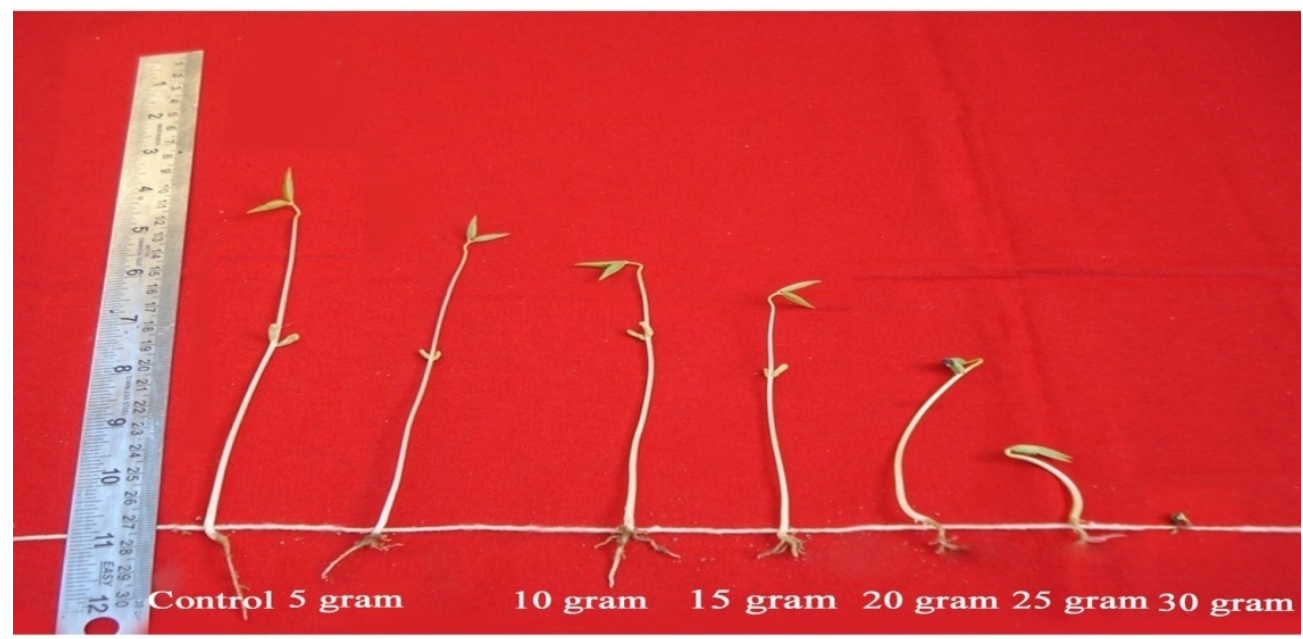

PLATE-II. Figure showing Measure of plumule and radicle in the seedling 


\section{DISCUSSION}

A cement industry offers an excellent opportunity for studying the impact of dust on germination, growth and yield of agriculture crops. The reaction of plants to pollutants can be seen from changes in plant communities and from visible lesions on leaves, flowers and fruits, as well as from invisible biochemical and physiological changes. The influence of pollutants also cause stress situation that affect the whole plant metabolism.

Seed germination is one of the most important phases in the life cycle of a plant and it shows highly response to existing environment (Besma and Mounir, 2010). Seed germination and seedling growth are vital for continuation of plant life. They are extremely vulnerable to environment stress due to presence of polluting agents in the environment especially during seed hydration period. The pollutants presence in the environment affect the germination and ultimately the growth and yield of the crop.

In the present study, the germination percentage of blackgram seeds gradually decreased with the increase in the level of cement dust treatments. Reduction in germination percentage was observed at $25 \mathrm{~g}$ of cement dust mixed with $200 \mathrm{~g}$ of soil. The better germination was observed at control sets. Similar results of the gradual decrease in seed germination percentage of blackgram, sunflower and groundnut crops were reported with increased amount of cement dust (Prasad and Inamdar, 1990; Zargari and Shoar, 2008 and Raajasubramanian et al., 2011). The decrease in germination of seeds with increasing concentration of cement dust may be due to toxic effect of metals present in the cement dust that interfere in the normal synthesis of metabolic products (Singh and Srivastava, 2002).

In contrast to that view, Saralabai and Vivekanandan (1992) reported that the application of cement dust to the soil did not affect the seed germination of some legumes. $100 \%$ germination was observed even at $200 \mathrm{~g}$ of dust mixed with $1 \mathrm{~kg}$ of soil. The observed positive effects may be attributed to the presence of optimum level of plant growth promoting elements $(\mathrm{N}, \mathrm{P}, \mathrm{Ca}$, $\mathrm{Mg}, \mathrm{Mn}, \mathrm{Fe}, \mathrm{S}, \mathrm{Cu}, \mathrm{Pb}$ and $\mathrm{Zn}$ ) in the cement dust. The germination of some leguminous seeds was totally affected in higher cement concentration. The time taken for plumule and radicle emergence was also delayed at increasing concentrations of the cement dust (Sundaramoorthy et al., 1997).

The seedling stage is the most sensitive stage in the life of a plant and more susceptible to physical and chemical adversities. In the present study, the reduction in the root and shoot length of blackgram seedlings grown in cement dust was recorded. It was observed that the seeds germinated even in the high concentration of cement dust but their subsequent growth of seedlings was inhibited. Reduction in seedling growth with increasing concentrations of cement dust solution has also been observed in Phaseolus vulgaris, Vigna Sp., Lycopersicum esculentum, Clitoria ternatea and Helianthus annuus (Prasad and Inamdar, 1991; Singh, 2000; Singh and Strivastava, 2002 and Zargari and Shoar, 2008). Decrease in growth of seedling with increasing concentration of cement dust may be due to presence of toxic metals in the cement dust.

The weight of the seedling depends upon the growth behaviour of seedlings. In our present study, reduction in fresh and dry weight of seedling grown in cement dust polluted soil were recorded. Similar results of reduction in dry weight of seedling were reported in wheat (Simba, 1986), some legumes (Saralabai and Vivekanandan, 1995), Tamarindus indicus (Sundaramoorthy et al., 1997), tomato (Singh, 2000) and groundnut (Raajasubramanian et al., 2011). The reduced dry weight may be due to the poor growth of seedlings grown in cement dust polluted soil.

Vigour index is the value of multiplication of seedling growth with germination percentage of seeds grown in respective doses. The value shows the ability of seedling growth in polluted environment. In our study, the value of vigour index was directly proportional to the amount of cement dust applied. Similar trend of variation in vigour index values was already recorded in various crops (Raajasubramanian et al., 2011). The variation in these values may be due to germination behavior of blackgram seedling grown under cement dust polluted environment.

Tolerance index value is obtained by dividing the root length of cement dust treated seedling with root length of control seedlings. It showed a decreasing trend with the increasing concentration of cement dust. Similar trend of tolerance index value was reported in various crops (Sundaramoorthy et al., 1997 and Raajasubramanian et al., 2011) exposed to cement dust pollution. The variation in these values may be due to response of root growth of seedlings grown in cement dust mixed soil.

Field experiments were conducted with blackgram crop dusted with varying levels of cement dust. In this field experiment, the root length and shoot length of blackgram gradually decreased with the increase in cement dust concentration. Similarly, the highest root length and shoot length were observed in (unpolluted) control plants than the polluted (treatment) ones. Similar growth reduction results were reported in 
various crops such as Hibiscus abelmoschus Cajanus cajan (Prasad et al., 1991) and sun hemp (Uma et al., 1994), Vigna mungo and Vigna faba (Kaushik, 1996); Triticum sativum and Betal vulgaris (Singh et al., 2003, 2005); some plants (Ademilua and Umebese, 2007) and groundnut (Raajasubramanian et al., 2011) due to the addition of cement dust.

A thin and hard crust of cement was formed on the upper surface of leaves of cement dust sprayed plants. The crust formation reduced the rate of photosynthesis. The reduction in plant growth due to environmental pollution which cause decreased photosynthesis (Gupta and Mishra, 1994). Presence of toxic pollutants in dust might be responsible for the reduction in plant growth. Traces of toxic metals like $\mathrm{Cr}$ and $\mathrm{Cd}$ present in cement are harmful to human beings and other living beings (Iqbal and Shafig, 2001).

The heavy metals and toxic pollutants present in cement dust can play an important role in disturbing the various metabolic processes and cause the reduction in plant growth. The growth of the plant is determined by genetic constitution and also by the edaphic and weather conditions, especially temperature and water regimes. It also depends upon the dust load, the duration of its effect and the tolerance of the plants. The growth reduction in shoot and root length might be due to deacidifying ability of cement dust by neutralizing the soil $\mathrm{pH}$ (Gajek et al., 1984). The presence of $\mathrm{Ca}^{++}$in the cement dust polluted soil decreased the availability of other nutrients needed for plant growth. The reduction in nitrogen content is the main causes of growth reduction in polluted plants. It may be due to reduced photosynthesis, interference with the gaseous exchange of foliage, clogging of stomata and interception in the incident light. The growth reduction may also be due to cement encrustation on the leaf surface, pigment degradation and intra or inter cellular changes in the leaves (Shukla et al., 1990).

Nodules are spherical or cylindrical growth formed in the roots of leguminous crops. They are formed as a result of an infection by bacteria (Streeter, 1995). They play a vital role in the process of nitrogen fixation in leguminous crops. In the present study, the reduced of nodules were recorded in blackgram, dusted with varying levels of cement dust. The nodule number is directly proportional to the amount of cement dusted blackgram crops. Similar results of decrease in the number of root nodules were reported due to cement dust in various crops such as Chickpea (Rai et al., 1984); Lupine (Tang et al., 1990); French bean (Thangarasu, 2002) and Common bean.

The reduction in number of nodules may be due to the increased deposition of cement dust in the soil that alters the soil $\mathrm{pH}$. The increased soil $\mathrm{pH}$ has an inhibitory effect on nodulation (Paz et al., 1982). The poor development of root nodules may be due to poor inhalation of nitrogen fixers in cement dust polluted soil (Stratmann and Van Haut, 1966 and Lie, 1974). It may also be possibly due to the deposition of cement dust pollutants which may become toxic to the population of Rhizobium as suggested by Thangarasu et al. (2002). The decreased number of nodule was recorded in soybean. Peanut (O'Hara, 1988) and French bean (Hemantarajan and Garg, 1986) due to iron deficiency.

In general, Leaf area is an important part of the plant responsible for conversion of solar energy. It is the index of photosynthesis which reflects into the crop production. Leaf is the most sensitive and reliable part of a plant than any other part. It may act as a persistent absorber and is exploited in polluted environment. The air pollution injury brings about a reduction in the number of leaves and leaf area (Krishnamurthy et al., 1994). In the present study, significant reduction in leaf number and total leaf area was recorded in blackgram crop due to cement dust pollution. Similar trends of reduction in number of leaves and total leaf area were reported in maize (Parthasarathy et al., 1975); wheat (Singh and Rao, 1980); some legumes (Indirabhai, 1987) Cassia carandas, Azadirachta indica and Delonix regia (Iqbal and Shafig, 2001). The harmful effects of dust deposition reduced the total leaf area due to uniform coating over the surface of the leaves, plugging of stomatal apparatus and impaired gaseous exchange (Krishnamurthy and Rajachidambaram, 1986).

The fresh and dry weight is mainly based on their growth performance of a particular crop. In our study, the reduction in fresh weight and dry weight of blackgram crop grown with cement dust were recorded. Similar results of reduced phytomass of plants were recorded in cotton (Armbrust, 1986), blackgram (Prasad and Inamdar, 1990), cotton (Satao et al., 1993), Sorghum (Chitralekha and Dhashinamoorthy, 2000) Atriplex halimus (Fakhry and Migahid, 2011). The phytomass of dusted plants was consistently lower than those of control plants at all stages of growth and again reduction was related to application rate of cement dust (Shukla et al., 1990). The decreased phytomass may be due to reduction in photosynthesis of polluted plant. The cement dust deposited on leaves reduce the available light for photosynthesis (Lerman, 1972). This may be due to reduced photosynthesis, through combination of factors such as reduced leaf area, clogging of stomata, interception of incident light due to cement encrustation on leaf surfaces, pigment degradation and inter or intracellular changes in the leaves.

The growth and yield are the most of useful criteria for determining economic damage of vegetation in polluted area. The yield parameters of blackgram such 
as number of pods, number of seeds/plant, 100 seed weight and yield are gradually decreased with the increase in cement concentration.

Alkaline cement dust deposition on plant leaves are known to reduce amount of light available for photosynthesis and reacting with water to form toxic solution. As a result, it reduced yield of crops without showing any visible leaf injury (Manning, 1971). Reduction in yield of rice, grape, cotton and barley was recorded when they are growing in the higher concentration of cement dust. Satao et al., (1993), has reported that the yield of wheat crop cultivated in field polluted with cement dust reduced and expressed in term of biological and economic yield. Shukla et al. (1990) reported the number of pods per plant and number of seeds per pod were found to be reduced. The characteristics of seed produced from dusted blackgram plants were markedly different from those obtained from the non-polluted site. The number and dry weight of seeds from dusted plants were significantly lower than those of control plants (Kumari and Pandey, 2011).

Inhibition of plant yield from polluted sites was always lower than control due to deposition of dust particles on the leaf surface that indirectly affects the metabolism of plants in various ways. The reduction in number of seeds was recorded in polluted area it may be due to failure of pollen germination on the dust laden stigma and failure of fertilization. The decrease in yield may be due to the poor growth of plants and their metabolism due to cement dust pollution. The heavy metals present in cement dust can play an important role in distribution the various metabolic processes.

Reduction in yield was primarily due to failure of pollen germination and fertilization on the dust - coated stigmatic surfaces. The reduction in production of flowers, pods and seeds were recorded in Brassica campestris and Brassica oleracea exposed to cement dust pollution for longer period (Shukla et al., 1990 and Zargar et al., 1999) respectively.

\section{REFERENCES}

Ademilua, O.E and C.E. Umebese, 2007. The growth of Phaseolus vulgaris L. (Leguminosae) in a cement site rich in heavy metals. Pak. J. Biol. Sci., 10: 182-185.

David, J.E and J. Fernandes, 1988. Industries categorized for pollution control. Environ. Res. Abs., 6: 7.

Demooy, C.J and J. Pesek, 1966. Nodulation response of soybeans to added phosphours, potassium and calcium salts. Agron. J., 58: 275-280.

Gajek, Franciszek and Kazimiera Drazas, 1984. Fertilizing and deacidifying ability of the cement dusts. Pamiet Pulawski, 82: 209-228.

Gupta, A.K and R.M. Mishra, 1994. Effect of lime kiln's air pollution on some plant species. Poll. Res., 13: 1-9.
Hemantarajan, A and O.K. Garg, 1986. Introduction of nitrogen-fixing nodules through iron and zinc fertilization in the non-nodule forming French bean (Phaseolus vulgaris L.). J. Plant Nutrition. 9: 281-288.

Indirabhai, K., S. Dhanalakshmi and K.K. Lakshmanan, 1988. A significant observation on the effect of cement kiln dust $\mathrm{H} 2 \mathrm{~S}$ and $\mathrm{NaCl}$ on growth and development of Dolichos biflorus. Adv. Pl. Sci., 11: 91-101.

Krishnamurthy, R., T. Srinivas and K.A. Bhagwat, 1994. Effect of air pollution on some bund trees of the agricultural lands. J. Environ. Biol., 15: 97-106.

Lerman, S., 1972. Cement kiln dust and the bean plant (Phaseolus vulgaris) in depth investigation into Plant morphology, Physiology and Pathology. Ph.D. Thesis, University of California, Riverside.

Manning, W. J., 1971. Effects of limestone dust on leaf condition, foliar disease incidence, and leaf surface microflora on native plants. Environmental Pollution, 2: 69-76.

O'Hara., G.W., M.J. Dilworth and N. Boonkerd, 1988. Iron deficiency specifically limits nodule development in peanut inoculated with Bradyrhizobium. New Phytol., 108: 51-57.

Pawar, K., L. Trivedi and P.S. Dubey, 1982. Comparative effects of cement coal dust and fly ash on. $\mathrm{H}$. abelmoschus. Int. J. Environ. Stud., 19: 221-223.

Paz, L.G., G.P. Ruschel and E. Malavolta, 1982. Effect of combined $\mathrm{N}, \mathrm{pH}$ and $\mathrm{P}, \mathrm{Ca}, \mathrm{Al}$ and $\mathrm{Mn}$ concentration in a culture solution on growth and $\mathrm{N} 2$ fixation in beans (Phaseolus vulgaris L.). Annais da Escola superior de Agricultura 'Liiz de Queiroz. 39: 189-201.

Prasad, M.S.V and J.A. Inamdar, 1990. Effect of cement kiln dust pollution on blackgram (Vigna mungo L.). Proc. Indian Acad. Sci., (Plant Sci.), 100: 435-443.

Prasad, M.S.V and J.A. Inamdar, 1991. Effect of cement kiln dust pollution on growth and yield of Vigna sp. Indian J. Ecol., 18: 91-94.

Raajasubramanian, D., P. Sundaramoorthy, L. Baskaran, K. Sankarganesh, Al.A. Chidambaram and M. Jaganathan, 2011. Effect of Cement dust pollution on germination and growth of groundnut (Arachis hypogaea L.). International Multi-disciplinary Research Journal 1: 25-30.

Raajasubramanian, D., P. Sundaramoorthy, L. Basnaran, K. Sankarganesh, Al.A. Chidambaram and M. Jaganathan, 2011. Cement dust pollution on growth and yield attributes of groundnut (Arachis hypogaea L.). International Multi-disciplinary Research Journal 1: 3136.

Raajasubramanian Devarajan , Krishna Ram Hanumappa and Narendra Kuppan 2015. The study of change in physicochemical properties of soil due to cement dust pollutionan hazardous terrorization to ecosystem; Canadian Journal of Pure and Applied Sciences Vol. 9, No. 1. 
Rai, R., V. Prasad S.K. Choudhury and N.P. Sinha, 1984. Iron nutrition and symbiotic N2 fixation of lentil (Lens culinaris) genotypes in calcareous soil. J. Plant Nutr., 7: 399-405.

Sagar, V.K., C.P. Gregory and S.J. Paul, 1982. Air pollution an important issue in plant health. Plant Dis., 66: 429-434.

Satao, R.N., H.K. Keue, R.V. Nalamwa and R.B. Vlemal, 1993. Effect of cement dust pollution on growth and yield of cotton. Ann. Plant Physiol., 7: 73-77.

Shukla, J., J.V. Pandey, S.N. Singh, M. Yunus, N. Singh and K.J. Ahmad, 1990. Effect of cement dust on the growth and yield of Brassica campestris L. Environ. Poll., 66: 8188.

Singh, A., S.B. Agrwal and D. Rathore, 2003. Growth response of wheat (Triticum sativum L.) exposed to ambient air pollution under varying fertility regimes. Sci. World J., 3: 799-810.

Stratmann and Van Haut, 1966. In: E.F. Darely., studies on the effect of cement kiln dust on vegetation. Air Poll. Con. Ass. J., 165: 33-39.

Streeter, G.J., 1995. A new model for the rapid effects of nononvasive treatments on nitrogenase and respiratory activity in legume nodules. J. Theor. Biol., 174: 441-452.
Tang, C., A.D. Robson and M.J. Dilworth, 1990. The role of iron in nodulation and nitrogen fixation in Lupinus angustifolius L. New Phytol., 114: 173- 182.

Thangarasu, S., 2002. Compared field investigations on structural and functional aspects of few crops under natural exposure to cement kiln dust Ph.D thesis Bharathidasan university.

Trag, S., Tanvirali, Mahmooduzzafar, O. Tariq Siddiqi and Muhammad Iqbal, 2001. Foliar responses of Zizyphus mauritiana L. To emissions of a coal-fired thermal power plant. Adv. Plant Sci., 14: 229-235.

Turner, R.G and C. Marshal, 1972. Accumulation of zinc by subcellular of root of agrostis tannis sibth in relation of zinc tolerance. New Phytologist., 71: 671-676.

Uma, C.H and T.V.R. Rao and J.A. Inamdar, 1994. Morphological changes due to cement kiln dust pollution on impact of Sunhemp (Crotalaria juncea L.). Phytomorphology, 44: 223-229.

Yahaya, T and J. Okpuzor, 2011. Variation in the degrees of exposure to cement dust in relation to distance from Cement Company. Res. J.Environ. Toxicol., 5: 203-212.

Yoshida, S., D. Fordo, J. Cork and K. Gomez, 1972. Laboratory manual for physiological studies of rice 3rd Ed., The International Rice Research Institute, Philippines, pp. 11-23. 